\title{
The Dimension of the Physical Education Teacher's Role as Support for the Inclusive Perspective
}

\author{
Gaetano Raiola ${ }^{1}$, Tiziana D'Isanto ${ }^{2}$, Antonetta Manna ${ }^{2}$ and Gaetano Altavilla ${ }^{3}$ \\ 1. Department of Human, Philosophical and Educational Sciences, University of Salerno, Fisciano, Salerno 84084, Italy \\ 2. MIUR, USR Campania, Napoli 80100, Italy \\ 3. Department of Human Sciences, University of Basilicata, Potenza 85100, Italy
}

\begin{abstract}
The article investigates on the educational value and upon the teacher of support, trying to clarify some aspects of inclusive education and school integration. Starting from the central role of the teacher of support is analysed by the task of its educational dimension, the different competences that are required to him, the aspects linked to the action of didactic that teachers can intervene to increase the level of integration and inclusion in the classroom, the best possible practices to be used in the classroom in order to better value the individual differences and to increase the highest possible educational success for students with special educational needs. Finally, it is hoped the use of cooperative learning, rather than learn by competitiveness and individualistic, since encourage more interaction between disabled and non-disabled students, a greater empathy between them, without forgetting that inclusive education is facilitated in school environments in which the teaching is active and where difficulties and problems that arise are analyzed to produce improvements.
\end{abstract}

Key words: Integration and inclusion, educational relationship, inclusive didactic, class group.

\section{Introduction}

The scholastic and social integration of students with disabilities in Italy is a cultural irreversible process and in continuous progress, even if it remains inside some contradiction between what is invoked and expected and what is actually achieved [1]. In particular, reference is made to teacher training, to all the resources needed for educational and social support activities, at the educational organization and the consequent risks of delegation and the subsequent isolation of the student with disabilities/special education teacher, as well as at the institutional and professional indispensable synergies. Speak of disability today, wants to say, adopt a vision of man who considers the very beginning of its existence as a person with rational abilities, emotional and affective, as a bearer concrete physical and mental needs [2]. Starting from the positive conception of difference, it

Corresponding author: Gaetano Altavilla, MD, Ph.D. candidate, research field: sports pedagogy. understood as the way to express itself of reality and not as a contraposition of categories [3, 4] and from the limit that it puts, it seems possible operate between exclusion and inclusion. An environment that wants to be characterized as inclusive must close the gap between able-bodied and disabled, by removing barriers to participation and learning [5] is a task that concerns everyone (teachers, pupils, school manager, family, technical assistants, local health services, educational assistants), since the effects are manifested throughout the school environment. It would then be important to eliminate the basic misunderstanding that occurs when we talk about inclusion and integration; the two concepts, although similar, give rise to a sort of antinomy. In the school context, "the paradigm to which implicitly refer the idea of integration is that one assimilationist, based on the adaptation of the student with special educational needs to the school organization, that is fundamentally structured as a function of the normal students" [6]; the inclusion presupposes an environment that can detect and 
remove obstacles that limit their participation and learning.

\subsection{The Figure of the Teacher of Support}

To borrow the words of Pope Francis is possible to imagine the support teacher as builder of bridges and networks between the different students, between students and teachers, between students and family, between school and family, between school and society. The teacher of support today takes on ever more specific and challenging tasks, as it is not only of support to individual student disabled but it is for the whole group-class, contributing to a harmonious integration and mutual cooperation. It is an essential figure, significant, both in relations with curricular teachers, both within the broader relationship with other professionals within and outside the school. The support teacher is an active mediator, is a neutralizer of conflicts and the promoter of a welcoming and inclusive school, able to provide appropriate responses to the specific learning needs and at social ones of each student [7]. The central unit of activity of the teacher of support is in the educational dimension of his task, which is to "take care" of the person, assuming both his special educational needs, both the deepest needs related to the dignity of the person as such, but that also involves the teaching action, the educational relationship, the relationship with colleagues, parents, the organization of the school system and culture in general. Between the needs of the persons that grow there is that of to be helped in the delicate phase of the maturation. The school is the place where this takes place in explicitly and institutional, with the commitment of varied professionalities, which make available their experience and expertise. They can be identified three components of the teacher professionality: cultural competence, didactic-methodologic competence and the psychological competence [8]. The cultural competency assumes, in addition to knowing well his own discipline, the ability to turn the interest of the students, to involve them in a group discussion arousing cognitive curiosity that is a prerequisite for a thorough analysis of a any topic. The second component, pedagogical, it is closely related to that didactic. In general, a good teacher should conceive the own teaching activities as research, that the teacher keeps open and in dialogue with the characteristics of individual students and goes continually adapted in afterwards to their answers [9]. The students, in fact, differ by type of intelligence, for to learn mode, for learning disabilities, for personality, for temperament and for appreciation in respect of the school and of the teachers; consequently it is good that the latter, while maintaining a unitary style are flexible enough to provide for the possibility of interventions targeted and personalized. This implies that must be cared the modality for relating with individuals and with the class because it is precisely the relationship between teacher and student that to determine the success or failure of the teaching-learning process [10]. It is natural that the inclusion of disabled students in the school determines changes in the professionalism of teachers. In principle, it becomes necessary to work in groups, where by group it means, beyond of the class council, also other institutional figures of reference [11]. Teachers must valorize the disciplinary areas of more interest, use in an integrated way the external resources and be available to keep up with new technologies and teaching materials. Help the student to grow as a person also means creating a personal relationship with the teacher; he should, at first place, to appear to each of his students as a person easily accessible, a point of reference to which, they can turn to for an immediate attention and listening [12]. The school during developmental age represents a fundamental context for the growth of the student with disabilities, without forgetting the purposes, namely instruct, educate, promote "well-being" at school and then a harmonic development of the student as a person. In this perspective, it is important that teacher reflects on own modality educational and relational used more 
frequently in the classroom, keeping in mind that a style of education open and flexible, in addition to creating a climate positive in class, is associated a sensibility greater towards to the discomfort of the students. A similar reflection on its educational style requires the teacher of get in discussion constantly and from time to time re-examine its own relational methods, which has structured in the course of own profession. Teach pupils with different types of needs is an aspect of knowing how to teach [13].

\section{Objective}

The aim of the study, theoretical argument, is to summarize the significant and overall aspects of the educational and formative value of support activities, through the key figure of the support teacher, taking into consideration the inclusive perspective.

\subsection{Special Educational Needs}

The integration education system is not suited to deal with the problems with which the school today is measured, in particular the steady increase within classes of pupils, even though without handicap certificate, present difficulties that depend on a multiplicity of Special Educational Needs. The phenomenon requires a new operational approach, starting with a change in the system evaluation and taking charge of the educational needs according the ICF model operating perspective [14]. The Individualized Education Program should not mean a separation from the disabled student, from a membership to a class or to a school context, but that allows him to do a different route that can lead to common goals to his peers [15]. The teacher of support have to represent a node of the network and the coordinator same network, a teacher who actively supports, the different skills in the school life of all and that it is not encloses in an individual educational relationship with the disabled student [16]. In this role, the support teacher must work in synergy with colleagues, an essential aspect, but not always feasible, to achieve the highest possible educational success. The student, however, can not be considered a taxable educational intervention recipient, but it must be the active protagonist of his own instruction and own education; Therefore the teacher's function is not to "doing lessons" but to create situations, itineraries of learning that allow students to operate at the physical and psychological level [17]. Obviously there cannot be a concept different of education for the subject with disabilities, in fact, for him education is to be understood as a process that must lead to a change in him, and that will take place only if the latter accept what that the teacher proposes; of course, the results will only be seen if the teachers have been able to push the student to want to learn [18].

\section{Methodology}

The most commonly used teaching methods yet seem those traditional, transmissive, mainly centered on the teacher, identical for all students, utilizing the textbook, individualistic, constructed on reading, explanation, study and verification [19]. This statement is also confirmed by some research [20,21], in which it is clear that the methodologies more commonly used in teaching appear still to be the frontal lesson and the text book compared to active methodologies and that are more appropriate at individualization, such as cooperative learning, the tutoring or the didactics laboratorial [22]. The aspects related to the action didactic on whose teachers can instead take action, to increase the level of integration and inclusion in the classroom, is certainly the adaptation of the materials, now practices well practiced by support teachers in order to valorize the individual differences. Adapt the materials respect to the different levels of skills and at the different cognitive styles produces the activation of multiple processing channels of the information. Moreover, it is necessary to pay attention to cognitive processes and at the learning styles of the students, because a truly inclusive education must valorize the different cognitive styles and the different forms of 
intelligence. Incentivize the use of mental and conceptual maps, diagrams and logical-visual strategies for all students with special educational needs, in fact, they result to be a great help for all forms of schematizing and organization of knowledge for the facilitation of learning. The assessment should always be formative, forms of personalized verification and a continuous use formative and motivating of the feedback and not punitive. Another resource that gives incentives are classmates, through the cooperation in couple or in small group and creating a good atmosphere in the classroom; because the learning processes are strongly influenced by the quality of the relationships, by the type of stimuli and by the class group. Finally, an important role is played by emotions in the learning process and in the relations, so that this happens there is need to create a good level of self-esteem and self-efficacy (self-efficacy is the confidence or belief that we have in our ability to learn), since the motivation to learn is deeply influenced by these factors. In fact, some of the personal processes to whom teachers must pay attention to, and modify if necessary: the self-efficacy, the motivation, the personal goals, the addiction, self-devaluation and distortion, the personal perfectionism, the sense of helplessness and the social comparison.

\section{Discussion}

The possibility of being part of a group becomes, in relation to the above considerations, important for a disabled person and the primary objective remains the building of inclusive relationships based on task. With heterogeneous classes, a clear goal is that among the students there is understanding and respect for differences of each, so that everyone can support and encourage the learning of the others. The cooperative learning offers an alternative valid, so that students collaborate together to achieve the educational goals and for facilitate good social relations. The cooperative learning experiences, compared to competitive and individualistic learning, they facilitate more interaction between disabled and non-disabled students and a greater empathy between them. Students can and should be invested the responsibility to accommodate and manage the disabled classmate, inventing ways of working so that he, too, be part of a system [23].

\subsection{Integration and Inclusive Model}

The fundamental resource on which is based the integration model is the teacher of support. Although the legislation provides that is a resource finalized to promote differentiated integration processes direct at the class [24]. In the inclusive model, instead, it must ensure that all teachers are trained to take responsibilities for all learners, regardless of their individual needs. In the inclusive school model, therefore, the teacher of support is a resource conceived as a system resource [25]. The inclusive education, in fact, it is facilitated in school environments where learning is active and where the difficulties and the problems that arise they are analyzed to produce improvements; it is, therefore, necessary to stimulate the active participation of students through cooperation and willingness to work in guided groups. The student with disabilities has a dual right, both the integration and either the right to specific answers and effective. The two things are not in contradiction, so how they are not the normality and the specialty, if we combine them in the "special normality" [26]. A need of normality, therefore, as an affirmation of the possession of the same rights as everyone else, of being the subject of value equal to that of all others and of to have equal opportunities; in the sense of being of equal value, although profoundly different.

\section{Conclusions}

In educational practice, much of the work falls back on the support teacher, a figure of teacher in the school has not yet found a precise role, but it is often identified as the only person to whom to delegate the problems relative at one or more disabled students. It is desirable 
to a school that guarantees everyone the right and duty to education and training through a variety of models, curricula and educational offerings, which give adequate and consistent responses at users increasingly diversified, by offering opportunities and options qualified level. A school, therefore, of inspiration European, which at the same time is deeply rooted in the traditions and national and local reality. A school that, through knowledge, the doing and the act, forms all the students as persons, face them to acquire knowledge and appropriate skills and, at the same time, prepare them the for insertion into the working world. In conclusion, the teacher of support must have clear its educational and formative role, accepting the student with disabilities as a whole, calibrating the targets related to the development of functional skills for his life, facilitating a gradual conquest of the autonomy, accompanying it for a portion of that path of change and growth that is proper to each one, indicating to him the necessary tools during this path. "Become a person with an initial individuality means to conceive the own realization in the terms of a true and own metamorphosis" [27].

\section{References}

[1] Chiappetta Cajola, L., ed. 2015. Inclusive Education. Evaluation and Orientation. Rome: Editorial Anicia. (in Italian)

[2] Leonardi, M. 2007. International Classification of Functioning, Health and Disability for Children and Youth, Introductory Note to the Italian Edition. Trento: Erickson. (in Italian)

[3] Deleuze, G. 1997. Difference and Repetition. Milan: Raffaello Cortina. (in Italian)

[4] Deleuze, G., and Guattari, F. 2003. Thousands of Plans. Capitalism and Schizophrenia. Rome: Castelvecchi. (in Italian)

[5] Booth, T., and Ainscow, M. 2002. The Index for Inclusion. Promote Learning and Participation in School. Trento: Erickson. (in Italian)

[6] Chiappetta Cajola, L. 2012. Teaching of the Game and Integration. Rome: Carocci Publisher. (in Italian)

[7] Bennardi, I. 2015. "Reflections of a Supporting Teacher in Inclusive School-Democratic Education." Political
Education Magazine. (in Italian)

[8] Petter, G. 2007. The Teacher's Craft. Florence: Joins. (in Italian)

[9] Arcari, A. 2008. Teens at School, in the Teacher of Education and Training, edited by Riva, M. G. Pisa: ETS. (in Italian)

[10] Kanizsa, S., ed. 2007. Educational work. The Importance of the Relationship in the Teaching-Learning Process. Milan: Bruno Mondadori. (in Italian)

[11] Giusti, M. 2006. Disability and High School. Florence: La Nuova Italia. (in Italian)

[12] Piazza, V. 2009. Supporting Teacher. Trento: Erickson. (in Italian)

[13] Altavilla, G. 2014. "Reading of Special Educational Needs." Acta Kinesiologica 8 (1): 66-7.

[14] Altavilla, G., Manna, A., and Perrotta, F. 2013. "A Possible Value in Terms of Education with Action Inclusive." Journal of Physical Education and Sport 13 (1): 371-4.

[15] Canevaro, A. 1999. Special Pedagogy. Reduction of Handicap. Turin: Mondadori Bruno. (in Italian)

[16] Ianes, D. 2001. Special Education for Integration. Trento: Ed. Erickson. (in Italian)

[17] Altavilla, G., Franco, F., Di Palmo, M., and Raiola, G. 2015. "Physical Skills, Sport Learning and Socio-Affective Education.” Sport Science 8 (Suppl. 1): 44-6.

[18] Jonnaert, P., and Vander Borght, C. 2003. Creating Learning Conditions. De Boeck: Bruxelles. (in French)

[19] Castoldi, M. 2009. Valuing Skills. Rome: Carocci Publisher. (in Italian)

[20] Ianes, D., Demo, H., and Zambotti F. 2010. Teachers and Integration. Trento: Erickson. (in Italian)

[21] Canevaro, A., Alonzo, L., Ianes, D., and Caldin, R. 2001. School Integration in Teachers' Perception. Trento: Erickson. (in Italian)

[22] Ianes, D. 2014. "Supporting Teachers: A Necessary Evolution." Italian Journal of Special Education for Inclusion (SI.Pe.S.), Pensa Multimedia-Lecce. (in Italian)

[23] Ianes, D., and Tortello, M., ed. 1999. The Quality of School Integration. Trento: Erickson. (in Italian)

[24] Ministerial Note of the 02/10/2002, $\mathrm{n}^{\circ}$ 4088-MIUR. (in Italian)

[25] Pavone, M., ed. 2004. "Supporting Teacher in a European Perspective." in School and Social Integration. Trento: Erickson. (in Italian)

[26] Ianes, D. 2006. The Special Normality. Integration and Inclusion Strategies for Disabilities and Special Educational Needs. Trento: Erickson. (in Italian)

[27] Xodo, C. 2001. Eye of the Heart. Brescia, Ed. La Scuola, 85. (in Italian) 